\title{
O CINEMA COMO FERRAMENTA PARA REFLEXÃO CRÍTICA SOBRE AS RELAÇÕES INTERNACIONAIS CONTEMPORÂNEAS: ANÁLISE DO INDIVÍDUO COMO SUJEITO DE DIREITO INTERNACIONAL A PARTIR DO FILME “O PORTO”.
}

\author{
CINEMA AS A TOOL FOR CRITICAL THINKING ON CONTEMPORARY \\ INTERNATIONAL RELATIONS: ANALYSIS OF THE INDIVIDUAL AS A \\ SUBJECT OF INTERNATIONAL LAW THROUGH THE FILM "LE HAVRE"
}

${ }^{1}$ Joséli Fiorin Gomes

\section{RESUMO}

As relações internacionais têm mostrado sinais de abertura à participação de diferentes atores, momento propício a erigir o indivíduo a sujeito do direito internacional. Uma ferramenta adequada para sensibilização quanto à questão se encontra no cinema, por proporcionar percepção mais concreta do tema. Com isso, obra apropriada para tanto é "O Porto" (Le Havre), a qual será analisada, na primeira parte do trabalho, a partir da teoria das relações internacionais, retomando postulados do "idealismo", no qual o direito internacional tem papel importante, a fim de, na segunda parte, verificar como aborda a participação do indivíduo no âmbito global.

Palavras-chave: Cinema, Indivíduo, Direito internacional

\begin{abstract}
International relations have shown signs of opening to the participation of different actors, a right time to elevate the individual as a subject of international law. A suitable tool for awareness on the issue is cinema, for it provides a concrete perception on the subject. Thus, an appropriate film is "Le Havre", which, in the first part of the paper, will be analyzed based on the theory of international relations, resuming postulates of "idealism", to which international law has an important role, in order to, in the second part, see how it addresses the individual's participation in global context.
\end{abstract}

Keywords: Cinema, Individual, International law

\footnotetext{
${ }^{1}$ Doutora em Direito pela Universidade Federal do Rio Grande do Sul - UFRGS, Rio Grande do Sul (Brasil). Professora convidada Universidade Federal do Rio Grande do Sul - UFRGS, Rio Grande do Sul (Brasil).

E-mail: joselifg@yahoo.com
} 


\section{Introdução}

As relações internacionais e o direito que as regula, o direito internacional, tradicionalmente identificados com as interações entre Estados e Organizações Internacionais, têm mostrado sinais de abertura à participação de diferentes atores. Tendo em vista a configuração de uma sociedade que vem ultrapassando fronteiras, movendo-se, consumindo e criando relações intersubjetivas em todo o mundo, seja de modo físico ou virtual, parece que este é o momento de o indivíduo, o ser humano passar a ser considerado como um elemento influente no delineamento das relações internacionais e, assim, como sujeito do direito internacional.

Nesse sentido, uma ferramenta adequada para buscar a sensibilização quanto a esta questão se encontra no cinema. Isso porque a linguagem cinematográfica, ao despertar emoções, proporciona uma percepção mais ampla e concreta dos temas discutidos no âmbito das relações internacionais, provocando a reflexão sobre estes, permitindo, a partir do desenvolvimento de capacidades criativa e crítica, a proposição de novas perspectivas e soluções quanto ao tema levantado. Ou seja, a linguagem cinematográfica, sendo utilizada para o debate de assuntos relativos às relações internacionais, serve como metáfora, já que

A realidade, o lugar onde estamos não pode ser visto enquanto estamos nele. É o processo de 'primeiro ou de segundo grau' (que se dá por meio das imagens, da alusão, da trama) que nos permite ver onde estamos e quem somos. A metáfora, em sentido amplo, é o modo como captamos (e às vezes quase entendemos) o mundo e nosso desconcertante self. (MANGUEL, 2009 , p. 55)

Com isso, a necessidade de lançar um olhar sobre o indivíduo, e identificar o seu papel no cenário atual das relações internacionais e do direito internacional, encontra no cinema um instrumento propício para a consecução desta tarefa. Nesse sentido, porque se busca refletir sobre este panorama em construção, um filme que se mostra apropriado a tal empreitada é a co-produção entre França, Alemanha e Finlândia intitulada "O Porto" (Le Havre).

Frente a isso, a referida obra cinematográfica será analisada do ponto de vista da teoria das relações internacionais e do direito internacional, para permitir a discussão sobre a possibilidade de inserção do indivíduo como sujeito neste cenário. Nesse viés, dentre as diversas doutrinas que conformam a teoria das relações internacionais, o filme abordado parece adequado para retomar postulados trazidos por uma perspectiva mais otimista das relações internacionais, identificada como "idealismo", para a qual o direito internacional tem 
papel importante, permitindo a consideração do indivíduo como seu novo sujeito. Portanto, na primeira parte do trabalho explorar-se-á como o filme retrata premissas defendidas pela teoria idealista das relações internacionais, para, na segunda parte, verificar como a referida teoria aborda a questão da participação do indivíduo no âmbito internacional, questionando se há mesmo espaço para ele nesta esfera.

\section{O filme "O Porto" (Le Havre) e a perspectiva idealista das relações internacionais}

O filme "O Porto" (Le Havre $)^{1}$, co-produção entre Finlândia, França e Alemanha, com roteiro e direção do finlandês Aki Kaurismäki, narra o encontro de um idoso francês, Marcel Marx (interpretado por André Wilms), com um menino gabonês, Idrissa (interpretado por Blondin Miguel). Marcel Marx é um ex-boêmio e escritor frustrado, morador da cidade portuária francesa de Le Havre. Sua vida é simples, desenvolvendo-se em volta de sua esposa, Arletty, do bar que frequenta e do serviço não muito lucrativo de engraxate, profissão que adotou depois desiludido quanto às suas ambições literárias. Sua rotina é alterada, no entanto, quando, ao sentar-se no porto, para comer o que trazia na sua habitual marmita, se depara com Idrissa. Este é um menino vindo do Gabão, o qual pretendia, com sua família, imigrar para a Inglaterra, país ao qual já imigrara a sua mãe. A família de Idrissa viajava num contêiner, transportado num navio, e fora descoberta pela inspeção local no porto francês, antes de chegar ao destino almejado. Idrissa consegue fugir dos inspetores franceses e se esconde nas águas abaixo dos pilares de sustentação da estrutura portuária. É ali que seu caminho cruza-se com o de Marcel, o qual decide, então, acolhê-lo.

A partir disso, o filme mostra o desenvolvimento de uma relação de amizade entre os dois personagens, que impulsiona Marcel a buscar meios de auxiliar o menino a encontrar os familiares e seguir sua viagem para a Inglaterra, a fim de reunir-se à sua mãe. Ao mesmo tempo, a esposa de Marcel fica doente, fazendo com que ele divida seus esforços entre ajudar o imigrante e cuidar dela, internada no hospital local. Com isso, a nova realidade de Marcel e sua relação com Idrissa comovem vários moradores da cidade, os quais se unem a eles na empreitada de angariar fundos para pagar a um navegador para levar Idrissa, em segurança, na travessia entre França e Inglaterra.

Nesse passo, o filme retrata uma bela lição sobre solidariedade e o reconhecimento do outro, do imigrante numa Europa cada vez mais temerosa quanto à chegada de

${ }^{1}$ O filme foi lançado em 2011, tendo participado da competição do Festival de Cinema de Cannes, França, no qual recebeu o prêmio da FIPRESCI (Federação Internacional de Críticos Cinematográficos). (FIPRESCI, 2013). 
estrangeiros. A trama mostra que as ligações humanas, manifestas em boas ações dirigidas ao próximo, podem efetivamente transformar a realidade, com atitudes de mais variadas amplitudes, “...desde a doação de um singelo pãozinho até um movimentado e bizarro show de rock..." (FILICIANO, 2012), que, além de auxiliar Idrissa, permite a retomada da carreira de um ícone real da cena musical europeia (Roberto Piazza, o Little Bob ${ }^{2}$ ).

Com isso, ainda que por meios que burlem a rigidez do tratamento oficial europeu ao estrangeiro migrante, as ações da comunidade de Le Havre demonstram o impacto e o papel da confiança e da união de forças individuais no mundo atual. Isto é, o enredo traz à cena o ser humano, resgata o protagonismo do indivíduo nas relações travadas em diferentes cenários, seja no plano interno estatal, seja no âmbito internacional. Atribui aos indivíduos e aos contatos sociais por eles estabelecidos a capacidade de alterar os fatos da vida cotidiana. Confere, então, à solidariedade um aspecto essencial nas relações humanas ${ }^{3}$.

\footnotetext{
${ }^{2}$ Roberto Piazza, nascido em 10 de maio de 1945, é italiano, mas cedo se mudou para o norte da França, para a cidade portuária de Le Havre. É também conhecido como Libero, pelo sobrenome de seu pai, um anarquista, que viveu na Itália de Mussolini. Naquela cidade da Normandia formou um grupo musical em 1975, o Little Bob Story, com inspiração no blues, rythm ' $n$ ' blues e no rock inglês dos anos 60 , do qual foi vocalista até sua separação em 1989. Atualmente, e já há onze anos, ele lidera um novo grupo, o Little Bob, que produziu quatro álbuns, com influência maior do blues (LITTLE BOB, 2013).

${ }^{3} \mathrm{O}$ termo solidariedade é polissêmico, que manifesta diferentes noções, sendo uma categoria controversa e discutida em diversos ramos científicos, tais quais o da filosofia, o da sociologia, o da política, entre outros correlatos. Contudo, segundo Westphal (2008, p. 44), nestas diversas concepções teóricas podem ser identificados dois aspectos comuns relativos à solidariedade, um substrato descritivo do termo, atinente à ideia da relação de reciprocidade entre os membros de um grupo e, outro, referente à base normativa da solidariedade, presente no cotidiano da política, da filosofia moral, da sociologia e do plano estatal. Nesse sentido, numa concepção inicial é identificada com conceito jurídico romano in solidum, que significa o dever para com o todo, a responsabilidade geral, a obrigação solidária, ou obligatio in solidum. Esta unia (e une) pessoas desconhecidas com papéis complementares e interesses heterogêneos, mediante um abstrato meio legal, dizendo respeito à "cooperação responsável de direito civil" (BRUNKHORST, 2002, p.10). Ainda, conforme Westphal (2008, p. 44) e Brunkhorst (2002, p. 12), a ideia de solidariedade apresenta outras duas fontes, quais sejam a ideia de unidade pagã-republicana (do grego homonoia e do latim concordia) e amizade civil (do grego philia e do latim amicitia), e a idéia bíblico-cristã de fraternidade (frat-ernitas) e amor ao próximo (caritas), denota que os cristãos, além dos laços consanguíneos, são irmãos em Cristo, o que os compromete ao amor ao próximo, o qual deve ser expresso em atitudes. A partir dessas concepções primárias, a sociologia contemporânea se apropria do termo, atribuindo-lhe sentidos autônomos que lhe conferem o caráter de solução às questões sociais do final do século XIX e inícios do século XX e de fundamento filosófico de uma nova ordem (HERRERA, 2013, p.64). Este movimento, segundo Herrera (2013, p.64), se inicia com Comte, o qual utiliza o termo para descrever um sentimento social, e se desenvolve como fundamento das repúblicas francesas, a partir dos trabalhos de Durkheim e Bourgeois, representando o direito, para o primeiro, o símbolo palpável da solidariedade social, e, para o segundo, sendo a solidariedade um direito natural, porque processo caracterizador da vida, em sentido biológico, implicando em um dever social de todos os seres humanos (HERRERA, 2013, p.65). Com isso, dá-se origem à teoria francesa do solidarismo. O solidarismo desenvolveu-se na virada do século 19 para o século 20 , influenciou a filosofia social e a política social francesas e a doutrina social da igreja católica, apresentando um conteúdo ético-normativo, objetivando a formulação de uma alternativa nos planos social, econômico e político, com um sentido consensual e universal, defendida por Gide e Bourgeois (WESTPHAL, 2008, p.45; TRAGL, 2000). Nesta teoria, a solidariedade é abordada em duas formas, a solidariedade natural, obrigatória ou de fato e a solidariedade dever, desejada ou geral (ZOLL, 2000). A primeira refere-se à consciência de pertencimento a uma comunidade, como, por exemplo, a família. As ações do indivíduo são influenciadas por este contexto e têm conseqüências no grupo a que pertence, emanando de interesses e convicções semelhantes, bem como por sentimentos de simpatia (WESTPHAL, 2008, p.45; TRAGL, 2000). Entretanto, esta forma de solidariedade não
} 
Nesse contexto, o exemplo de solidariedade retratado no filme permite compreender e retomar conceitos de um importante marco teórico no âmbito da teoria das relações internacionais ${ }^{4}$. Trata-se do idealismo ${ }^{5}$. Segundo Peter Wilson (2011, p. 332), este termo é utilizado em dois sentidos principais no estudo das relações internacionais, um mais amplo e outro mais estrito. No sentido mais amplo, representa uma doutrina caracterizada como otimista, a qual objetiva construir uma ordem mundial mais cosmopolita e harmoniosa; já no sentido mais estrito, é relacionado ao período entre as duas grandes Guerras Mundiais (19191939), distinguindo-se por uma doutrina baseada na crescente interdependência e unidade da humanidade, atrelando-se ao experimento internacionalista que foi a Liga das Nações. (WILSON, 2011, p. 232). Para abordar o idealismo, neste trabalho utilizar-se-ão ambos os sentidos, a fim de apontar seu impacto para o estudo das relações internacionais e verificar sobre a possibilidade de sua retomada hoje, para a participação do indivíduo neste cenário.

O idealismo normalmente é analisado, no âmbito da teoria das relações internacionais, a partir de seu contraste com a escola realista ${ }^{6}$, a qual se coloca em

soluciona os problemas éticos decorrentes da esfera econômica (WESTPHAL, 2008, p.45). A outra forma de solidariedade é a solidariedade desejada ou necessária, que advém da solidariedade natural, pois os indivíduos reconhecem que esta pode gerar desigualdades, precisando corrigir falhas de desenvolvimento social. A solidariedade passa, então, a ser uma categoria ética para criar movimentos preventivos para efetivação de liberdade e de humanidade (WESTPHAL, 2008, p. 46). Para que a solidariedade dever seja real e efetiva, é preciso a intervenção do Estado na condição de formulador da legislação referente às questões sociais, tendo papel coordenador da coesão social (TRAGL, 2000).

${ }^{4}$ Segundo Nunes (2012, p. 11), no estudo das relações internacionais a teoria é, por muitos, abordada como mero preâmbulo à análise da política internacional propriamente dita. Contudo, o autor sustenta que a teoria das relações internacionais deve ser vista a partir de três óticas diversas: a) como um instrumento de análise da realidade, descrevendo, prevendo e prescrevendo ações e seus efeitos; b) como forma de construção da realidade, enquanto processo social; constituindo um imaginário cultural e moral, que, ao configurar interesses, leva os agentes a agirem conforme seus preceitos; c) e como prática política, que reflete tensões sociais, configurações de poder e interesses, contribuindo para a produção e reprodução, ou mesmo transformação, da realidade (NUNES, 2012, p. 12-16). Então, conforme o autor, a teoria das relações internacionais serve como forma de intervenção no mundo, permitindo participar na definição da política internacional (NUNES, 2012, p.20).

${ }_{5}$ Apesar de ser considerada como parte do rol das grandes correntes teóricas das relações internacionais, há quem sustente, como Ashworth (2005, p.3-7), que nunca houve, de fato, uma teoria idealista unitária, mas, sim, vários autores cujas obras, apesar de sua diversidade, foram intituladas "idealistas", não sendo possível definir, pelo seu uso no estudo das relações internacionais, se se referia a um modo de pensamento, um instrumento aberto a quaisquer pensadores, ou se seria um modo de definir um grupo específico de pensadores.

${ }^{6}$ Trata-se de corrente hegemônica do estudo contemporâneo das relações internacionais (DIAS, 2010, p. 25), a qual trata basicamente, e quase de forma exclusiva, das relações políticas entre os estados, considerando válidas apenas as variáveis diplomáticas e militar-estratégicas (LACERDA, 2006, p. 59). Com inspiração nas teorias de Maquiavel e Hobbes, toma como princípio básico que o poder é o elemento que garante um mínimo de ordem no âmbito da sociedade internacional, substancialmente anárquica, sendo a ambição pelo seu domínio inerente aos homens, pelo sentimento de insegurança no mundo, o que faz com que, na existência de um poder superior uno, seja dever dos Estados velar pela segurança internacional (DIAS, 2010, p. 25; LACERDA, 2006, p.59). Surge em contraposição à corrente tachada como "idealista", tendo como maiores expoentes Edward Carr, com sua obra intitulada "Vinte anos de crise" (1981) e Hans Morgenthau, com a obra "A Política entre as Nações" (1985). São pressupostos básicos do modelo do realismo político o domínio do enfoque estatal, a separação da política interna e externa e a primazia das colocações quanto ao poder, partindo sua análise das relações internacionais como elas são, buscando entender seu funcionamento pela identificação dos princípios que as organizam, mediante uma concepção pessimista da natureza humana. Apresenta, assim, como premissas 
contraposição àquela perspectiva ${ }^{7}$. Contudo, segundo Soraya Nour (2004, p.109), as origens do idealismo podem ser localizadas nos ideais pacifistas de doutrinas ético-religiosas, como, por exemplo, o budismo, o judaísmo e o cristianismo, sendo que sua utilização na condução de assuntos políticos é encontrada ao longo da história humana (DIAS, 2010, p.20).

Nesse passo, de acordo com Trindade (2010, p. 82), são apontados como precursores do idealismo pensadores como Marsílio de Pádua ${ }^{8}$, Thomas Morus ${ }^{9}$, Hugo Grotius ${ }^{10}$, Abade

principais a ideia de Estados unitários e racionais, com interesses particularistas, o foco na segurança internacional, a anarquia do sistema internacional e a correspondente dificuldade de manutenção da paz entre seus atores, e a existência de relações de poder entre os Estados, fundadas em termos econômicos, militares e na opinião pública internacional (DIAS, 2010, p. 27). Além disso, a corrente realista recebe uma reinterpretação, passando a constituir o neorrealismo ou realismo estrutural, cuja principal referência é a obra de Kenneth Waltz, intitulada "Teoria das Relações Internacionais" (2002). Como teoria, o neorrealismo se coloca como um realismo defensivo, cujo pressuposto básico é o fato de que os Estados estão mais orientados à busca de segurança do que de poder, buscando manter suas posições no sistema internacional, não apresentando tendência expansionista, mas, sim, conservadora (DIAS, 2010, p. 29-30).

7 Segundo Ashworth (2002, p. 33), o estudo das relações internacionais é delineado a partir de suas narrativas históricas e nenhuma ideia, individualmente considerada, foi mais influente do que aquela que sustenta ter havido, durante os anos 1920 e 1930, um "grande debate" entre idealistas e realistas. Contudo, conforme o autor, na realidade, nunca houve um único "grande debate", mas, sim, uma multiplicidade de discussões que giravam em torno de três grandes perguntas: a) o capitalismo leva à guerra?; b) quais são as formas mais eficazes de lidar com a agressão do Estado totalitário?; c) para os EUA, é a retirada de alianças uma resposta razoável em um mundo abalado pela guerra e depressão econômica? Nesse período, o estudo acadêmico das relações internacionais permaneceu fortemente liberal. No entanto, para ele, o liberalismo nunca foi seriamente desafiado por um apolítico realismo, mas, sim, por críticos socialistas - pelo menos na Grã-Bretanha - e isolacionistas nos Estados Unidos. Em última análise, segundo ele, a persistência da noção de que houve um verdadeiro debate entre idealismo e realismo, que o último, aparentemente, ganhou, diz menos sobre as discussões reais da época, e muito mais sobre a marginalização do liberalismo e do pensamento normativo no cenário das relações internacionais do pós-guerra. Ainda, conforme o mesmo autor, a crítica realista de Carr nunca se referiu ao termo idealista, apenas tachando a seus rivais de utópicos. No entanto, a grande maioria das pessoas que foram criticadas por Carr e Morgenthau, e que, mais tarde, aparecem como idealistas nas notas de rodapé de livros didáticos de relações internacionais, tinham algo em comum. Eram todos, de alguma forma, liberais, e, frequentemente, eram liberais sociais ou social-democratas. Apesar disso, as ideias dos chamados idealistas cobria uma gama de diferentes abordagens ideológicas, metodológicas e epistemológicas que o uso do termo geral é, de um ponto de vista teórico, inutilmente amplo, e consequentemente, indefinível. Os "idealistas" como um grupo, conforme Ashworth, tinha, então, muito pouco em comum (2002, p. 36). Frente a isso, conforme Lacerda (2006, p.65), o interessante, e talvez curioso, é que não há, nem houve nenhum texto "científico" de relações internacionais elaborando o idealismo enquanto teoria. Ou seja, o idealismo foi combatido pelo realismo, mas apenas como prática de condução da política externa, e não como teoria acadêmica. Portanto, o realismo se constituiu como visão de mundo articulada em disciplina acadêmica para contrapor-se somente a uma certa visão de mundo que era praticada por alguns líderes políticos (LACERDA, 2006, p.65).

${ }^{8}$ Segundo Trindade (2010, p. 82), publicou sua obra, Defensor Pacis (2013), em 1324, a qual tratava sobre a paz e a guerra, formulando a ideia de comunidade perfeita, sob inspiração de "A Política", de Aristóteles, na qual as principais funções responsáveis pela paz centravam-se no governo, na deliberação e na justiça, tendo a autoridade política fundamento no povo, pelo voto ou pela manifestação pública de vontade.

${ }^{9}$ Conforme Trindade (2010, p.82), Thomas Morus, na obra "Utopia" (2013), discorre sobre uma ilha perfeita regida por leis e instituições, com governos escolhidos por famílias. Ainda, na sua obra se insere a ideia de guerra justa, pois apesar de na ilha a guerra ser tida como brutal e selvagem, seus habitantes podem auxiliar seus amigos a se defenderem ou a se vingarem de injustiças cometidas contra eles (TRINDADE, 2010, p.82).

${ }^{10} \mathrm{Na}$ obra De iure belli ac pacis (2013), Grotius, segundo Barnabé (2009:43), constrói seu pensamento jurídico com base no conceito de natureza humana. A natureza social e racional do homem, que é o fundamento do direito natural, traz como consequência a necessidade de se estabelecer regras mínimas para a sobrevivência da sociedade. A partir da obrigação de cumprir os pactos, o direito internacional é construído pelos Estados: na interação social entre os Estados, a conveniência e a reflexão racional dão origem às regras jurídicas mínimas que ordenam a sociedade internacional. De maneira geral, o direito de empreender uma guerra externa surge da 
de Saint-Pierre ${ }^{11}$ e Immanuel Kant ${ }^{12}$, dentre outros. Estes autores, apesar de não formarem uma corrente doutrinária una, apresentam traços comuns, identificados na crença quanto à constante evolução ética das civilizações (MIYAMOTO, 2004, p.25), tendo por objetivo central a transformação do sistema internacional em cenário estável de paz (DIAS, 2010, p. 20-21).

Com isso, estes desenvolvimentos doutrinários influenciaram, nos períodos entre as duas grandes guerras do século XX, a concepção de uma visão de mundo diferente (DIAS, 2010, p.21). Esta considerava a guerra como irracional, estranha à natureza humana, a qual ocorria por falhas de comunicação entre os Estados, devendo ser eliminada a partir da construção de organizações amplamente aceitas, que harmonizassem os diferentes interesses existentes no meio internacional (DIAS, 2010, p. 21).

Nesse sentido, o idealismo encontrou terreno fértil para se desenvolver na proposta para consenso político apresentada, em 1918, ao Congresso estadunidense pelo Presidente norte-americano Thomas Woodrow Wilson, composta de 14 (quatroze) pontos ${ }^{13}$, dentre os quais constava a proposição de criação de uma associação geral de nações para permitir-lhes

violação do princípio de convivência pacífica entre os Estados que, especificado por Grotius, compreende a defesa contra uma injúria, atual ou ameaçadora, mas não antecipatória; a recuperação do que é legalmente devido; imposição de punição. Introduzindo uma abordagem jurídica da guerra, esta se torna com Grotius a extensão de um processo judicial. A guerra pública solene é a expressão do formalismo jurídico se sobrepondo à justiça material da guerra. No seu pensamento, o conflito não é a marca exclusiva do sistema internacional, mas, com fundamento na própria natureza humana, os Estados cooperam entre si. A sociabilidade é a manifestação fundamental do direito natural, fornecendo as condições para se julgar o que é justo e o que não é. Para ele, o direito é a efetivação da natureza social e racional do homem e deve sempre imperar nas relações internacionais sob pena de guerra ou mesmo na guerra. (BARNABÉ, 2009, p. 44).

${ }^{11}$ Segundo Trindade (2010, p. 83), no primeiro quarto do século XVIII, entre 1713 e 1717, o Abade de SaintPierre apresentava proposição, na obra "Projeto para Tornar Perpétua a Paz na Europa" (2005), sobre a unificação de toda a Europa, agrupando as "soberanias cristãs" com o objetivo de tornar possível uma paz perpétua. Na sua proposta, as soberanias deveriam assinar um tratado de união e formalizar um congresso perpétuo, na tentativa de resolverem os problemas de constantes guerras, conservarem as suas existências e aproveitarem as vantagens do comércio entre nações.

${ }^{12}$ No presente trabalho, tendo em vista o destaque atribuído à contribuição kantiana para o idealismo e para o estudo das relações internacionais, tratar-se-á no corpo do texto, mais adiante, sobre os postulados presentes em sua obra.

13 Segundo Griffths (2004, p.148), os 14 (quatorze) pontos de Wilson sintetizavam suas ideias sobre política internacional, contemplando as seguintes propostas: 1) pactos de paz, diplomacia franca e pública; 2) liberdade absoluta de navegação dos mares e águas fora dos territórios nacionais, tanto na paz quando na guerra; 3 ) abolição de barreiras econômicas entre os países e estabelecimento de igualdade de condições de comércio entre eles; 4) redução dos armamentos nacionais ao menor nível necessário à garantia da segurança nacional; 5) reajuste livre, aberto e imparcial da política colonialista, atribuindo aos interesses das populações colonizadas o mesmo peso daqueles das nações colonizadoras; 6) retirada dos exércitos do território russo e solução das questões relativas à Russia; 7) restauração da soberania belga, com retirada das tropas alemãs; 8) libertação do território francês, restaurando-se as partes invadidas, especialmente a Alsácia-Lorena; 9) reajuste das fronteiras italianas; 10) reconhecimento do direito ao desenvolvimento autônomo dos povos da Ãutria-Hungria; 11) retirada de tropas estrangeiras da Romênia, da Sérvia e de Montenegro, restaurando os territórios invadidos e concedendo à Sérvia acesso ao mar; 12) reconhecimento da autonomia da Turquia e autogoverno limitado para nacionalidades até então sob domínio do Império Otomano; 13) independência da Polônia; 14) Criação de associação geral de nações sob pactos específicos, com propósito de fornecer garantias mútuas de independência política e integridade territorial dos grandes e pequenos Estados. 
garantias recíprocas de independência política e integridade territorial, o que influenciou, apesar da inicial não participação dos EUA, no estabelecimento, em 1919, da Liga das Nações (DIAS, 2010, p. 24; MIALHE, 2008, p. 220). Assim, a expectativa idealista era obter a paz pela repartição de poderes entre novas organizações internacionais, que, acima dos Estados, poderiam estabelecer normas para um maior entendimento entre eles. (DIAS, 2010, p. 21). É, então, tida como uma teoria normativista, que valoriza o direito internacional como forma de diminuição e/ou contenção da guerra, encontrando nas obras de Alfred Zimmern ${ }^{14}$, Norman Angell ${ }^{15}$, entre outros, seus principais desenvolvimentos no século XX (DIAS, 2010, p. 2122).

Diante disso, segundo Bedin (2001, p. 24-25), podem-se resumir as concepções fundamentais do idealismo nas seguintes ideias: a) a natureza humana não é de todo má, tendo princípios de cooperação e solidariedade; b) as formas democráticas de sociedade podem favorecer o comportamento internacional pacífico; e c) há a possibilidade de construção de instituições de abrangência planetária e preceitos ético-jurídicos universais. Ou seja, conforme Trindade (2010, p.83) denota-se que as concepções idealistas destacam valores éticosjurídicos e a capacidade racional humana, na tentativa de formular um conjunto de princípios universais para orientação das relações humanas, sejam sociais, sejam estatais, mediante o entendimento, a confiança e a boa-fé entre os diversos atores. Então, conforme Miyamoto (2004, p.15), o idealismo sustenta a necessidade de estruturar o mundo por princípios universais, em busca da compreensão, com condutas pacifistas, em que a confiança e a boa vontade sejam as causas que as impulsionem.

Isto é o que se vê no exemplo de solidariedade e confiança retratados no filme "O Porto", unindo o estrangeiro Idrissa e os europeus da comunidade de Le Havre, construindose um cenário propício para a discussão do crescente papel do indivíduo nas relações internacionais e sua possível elevação a sujeito de direito internacional, a fim de retomar os conceitos idealistas, especialmente os ideais cosmopolitas propostos por Kant. Sobre isso se tratará a seguir.

\footnotetext{
${ }^{14}$ Dentre suas obras, destaca-se "The League of Nations and the Rule of Law" (2013), na qual examina e avalia a Liga das Nações como organização destinada à condução das relações internacionais.

15 Segundo Dias (2010, p. 22), escreveu a obra “The Great Illusion” (2013), em 1910, que teve grande repercussão na época, em que considera a guerra como uma grande ilusão, em que todos têm a perder.
} 
2 Do idealismo nas relações internacionais ao reconhecimento do indivíduo como sujeito de direito internacional no cenário contemporâneo

Diante do que foi abordado na parte anterior, verifica-se que o idealismo apresenta uma visão otimista das relações humanas e internacionais, compreendendo o homem como um ser racional, capaz de resolver seus problemas mediante o diálogo, regulando suas condutas por normas ético-morais e jurídicas, possibilitando a criação de instituições internacionais que zelem pela paz pela utilização destas normas. Em face disso, o idealismo permite pensar sobre a participação que pode ter indivíduo no plano internacional.

Ainda, percebeu-se que a chamada corrente idealista não possui uma unidade doutrinária, mas reúne elementos similares de obras de autores das mais diversas áreas, não havendo autores canônicos especificamente do campo das relações internacionais (LACERDA, 2006, p. 66). Contudo, em decorrência da ênfase colocada sobre as relações humanas, resgatando o indivíduo à cena internacional, conforme Lacerda,

a abordagem ética das relações internacionais teve como grande teórico, ainda que no campo filosófico, o iluminista Immanuel Kant, autor do clássico opúsculo À paz perpétua, de 1795. (2006, p.66).

Nesta obra, Kant apresenta um projeto filosófico conforme o qual os Estados republicanos poderiam conviver sem guerras (TRINDADE, 2010, p.44). Em seus artigos preliminares, Kant (2013) estabelece as condições necessárias, baseadas em elementos empíricos, para a saída do estado de guerra e estabelecimento da paz perpétua entre os Estados, servindo para mediar as relações interestatais ainda no estado de natureza (TRINDADE, 2010, p. 45; TERRA, 1997, p. 224-225; LIMA, 2012, p. 472). Já nos artigos definitivos, ele formula a argumentação para uma imperiosa busca da paz mediante estruturas jurídico-institucionais criadas com vistas ao estabelecimento de um estado civil (TRINDADE, 2010, p. 50). Nesse sentido, Kant demonstra que a ausência de leis, o estado de natureza conforma uma situação potencial de guerra, sendo necessária a instauração da paz pela elaboração de estatutos jurídicos em todos os níveis de relações humanas, isto é, no Direito Público (nas relações entre indivíduos), no Direito das Gentes (nas relações entre Estados) e no Direito Cosmopolita (nas relações entre indivíduos e Estados) (TRINDADE, 2010, p. 51).

É neste ponto que Kant inova, pois, de acordo com o que sustentam Trindade (2010, p. 57) e Nour (2003, p. 21), até este momento o Direito apresentava apenas duas dimensões, a do Direito Estatal, das relações internas, e a do Direito das Gentes, das relações externas, trazendo "À paz perpétua" uma terceira dimensão, a do Direito Cosmopolita, dos cidadãos do 
mundo, em que o indivíduo não é somente parte do Estado, mas membro da sociedade internacional cosmopolita. Ou seja, para Kant, esta terceira dimensão jurídica se pauta pela ocupação e convivência comum dos homens sobre a extensão limitada do mundo, em que cada indivíduo faz parte de um sistema em que uma ameaça ou violação a direito em qualquer lugar repercute da mesma forma para todos, já que ninguém possui mais ou menos direito de estar sobre o planeta (NOUR, 2004, p. 55-56).

Em face disso, o Direito Cosmopolita é apresentado por Kant como a terceira condição positiva para a paz, estabelecendo-se a partir do princípio de que todos, originariamente, possuem o mesmo direito sobre o solo, que não é um direito "adquirido", mas decorrente do direito natural à liberdade (NOUR, 2003, p. 22). Deste direito se depreende o direito sobre o próprio corpo, o qual, ao precisar de espaço, gera a propriedade originária coletiva sobre o solo (KANT, 2013; NOUR, 2003, p. 22). Desta se origina o "direito de visita" (KANT, 2013), ou seja, o direito do cidadão do mundo de tentar a comunidade com todos e, para tanto, de visitar todos os lugares do planeta, bem como o "direito à hospitalidade" (Kant, 2013), o direito de, na tentativa de se relacionar com os outros, não ser tratado pelo estrangeiro como inimigo. A violação a este direito ocorre, então, quando aquele que chega a um lugar não é aceito pelos que ali já estão (NOUR, 2003, p.22).

O direito cosmopolita opõe-se, assim, a um direito de estabelecimento (Kant, 2013) sobre o território de um outro povo (NOUR, 2003, p. 22). Ou seja, sustenta-se que o indivíduo seja respeitado como cidadão do mundo e na sua possibilidade de estabelecer relações com os Estados e outro indivíduos, mas se coloca uma limitação a estas condição e possibilidade do indivíduo, repelindo-se a colonização ou conquista de outro povo. Com isso, a violação ao direito cosmopolita pode ocorrer tanto quando um Estado nega ao estrangeiro acesso ao seu território, aos bens e relações jurídicas com seu povo, como quando o estrangeiro, indevidamente, toma para si a terra e os bens ou explora as pessoas do Estado visitado (TRINDADE, 2010, p. 59-60). Nesse viés, Caimi (1997, p. 192), indica que há duas tendências de interpretação do cosmopolitismo kantiano, a que o entende como o direito de se mover pelo mundo e visitar terras alheias, e a que o percebe como direito de reciprocidade de tratamento entre Estados e entre indivíduos de Estados diversos. Porém, ele aponta que ambas as interpretações coexistem na concepção kantiana, sendo a primeira o sentido imediato do terceiro artigo definitivo de "À paz perpétua", enquanto a segunda contempla seu sentido mediato, de delimitação das condições unipessoais necessárias à hospitalidade e à proibição do colonialismo (CAIMI, 1997, p. 192). 
Assim, retomar o idealismo de vertente kantiana, frente ao tema aqui abordado, parece adequado, já que, nas formulações em prol da paz perpétua, ele insere o indivíduo em lugar de destaque nas relações internacionais. Ainda, aparenta relevância porque traz uma ideia de paz adequada ao contexto hodierno, marcado pela “...massiva desigualdade na distribuição dos recursos, a interdependência econômica, o pluralismo cultural associado às vezes com nacionalismo, separatismo étnico e fundamentalismo religioso, as armas nucleares...” (NOUR, 2003, p. 8). Então, conforme Trindade (2010, p. 305), percebe-se “...que é válida a releitura dos diversos elementos do pacifismo kantiano, sejam de natureza interna, interestatal ou cosmopolita, pois com as devidas ponderações em razão do transcurso temporal de mais de 200 anos, tais elementos ainda são de grande atualidade...”.

Frente a isso, é uma postura, ainda que inconsciente e/ou acidental, cosmopolita, kantiana, idealista que a comunidade de Le Havre, liderada por Marcel Marx, quanto a Idrissa, o estrangeiro, o visitante, o que se pode presenciar no filme em comento. As diversas ações que se somam ao longo da trama para auxiliar o menino a seguir sua jornada ao encontro da mãe parecem apontar que é possível a concretização do "direito de hospitalidade" kantiano, já que o visitante é recebido, ainda que com inicial desconfiança, com dignidade, não sendo tratado como inimigo, mas como uma pessoa que necessita do amparo de seus pares na comunidade humana e o recebe, a despeito do que o direito estatal e internacional preveem (representados na perseguição policial que se desenvolve durante o enredo).

E, esta é a condição que se busca garantir aos indivíduos de todo o mundo mediante os diversos tratados internacionais relativos a direitos humanos ${ }^{16}$, elaborados no seio de organizações internacionais de cunho universal e regional, frutos do idealismo nas relações internacionais. Do mesmo modo, é o que se pretende assegurar pela instituição de mecanismos de proteção para os direitos inseridos nestes tratados, pelas atribuições dadas a essas organizações internacionais para reconhecerem as ações ou as omissões dos Estados no

\footnotetext{
${ }^{16}$ Segundo Cançado Trindade (1999), diferentemente dos tratados tradicionais, os tratados de direitos humanos prescrevem obrigações de caráter objetivo, a serem implementadas coletivamente, e procuram garantir o interesse geral, transcendendo os interesses individuais das Partes Contratantes. Dentre as normas internacionais, sejam ou não classificadas como tratados, que preveem direitos humanos destacam-se a Declaração Universal dos Direitos do Homem, de 1948; a Convenção sobre a eliminação de todas as formas de discriminação racial, de 1965; os Pactos de Direitos Civis e Políticos e de Direitos Econômicos, Sociais e Culturais, de 1966; a Convenção sobre a eliminação de todas as formas de discriminação contra a mulher, de 1979; a Convenção contra a tortura e outros tratamentos ou penas cruéis, desumanos ou degradantes, de 1984, dentre outras, celebradas no âmbito da Organização das Nações Unidas. Ainda, no plano de organizações de cunho regional, podem-se destacar as Convenções Europeia e Americana e a Carta Africana referentes a direitos humanos, respectivamente, de 1950, no âmbito do Conselho da Europa, de 1969, no âmbito da Organização dos Estados Americanos, e de 1981, no seio da União Africana.
} 
cumprimento de tais direitos ${ }^{17}$. Ainda, há certa inserção do indivíduo, tanto como sujeito de direitos como de deveres no plano internacional, no âmbito do direito humanitário e do direito criminal internacional, especialmente no contexto de conflitos $\operatorname{armados}{ }^{18}$. Assim, segundo Cançado Trindade (2002, p. 5-6), deve-se reconhecer ao indivíduo a condição de sujeito de direito internacional, em razão de a ele se atribuírem direitos e deveres, com capacidade processual para buscar a garantia daqueles e sofrer as consequências das violações destes.

Contudo, constata-se que esta não constitui uma opinião unânime e uniforme ${ }^{19}$ e que as possibilidades de efetiva participação e influência dos indivíduos no cenário internacional está, ainda, longe do almejado pelas esperançosas previsões contidas nas atuais normas internacionais. Isso se justifica na medida em que, apesar do reconhecimento de direitos humanos, de responsabilização no âmbito dos direitos humanitário e criminal internacional, ainda há objeções que são levadas em conta pelos demais atores internacionais para impedir a performance do indivíduo nesse cenário. Essas objeções relacionam-se a não atribuição aos indivíduos de todas as mesmas faculdades inerentes aos demais sujeitos tradicionais do direito internacional, como a capacidade para participar da produção de normas internacionais, a limitada capacidade de agir, ou seja, de praticar atos válidos e de reclamar pela garantia de seus direitos no plano internacional (DRI, 2005, p. 11), o que faz com que alguns estudiosos, como Ventura e Seitenfus (2003, p. 114), os considerem como sujeitos incapazes, por entenderem que a capacidade de agir como elemento determinante da personalidade jurídica.

Diante disso, segundo Clapham (2010, p. 29-30), há que se perguntar se a inserção do indivíduo no âmbito internacional se encontra em progresso ou em estagnação, se

\footnotetext{
${ }^{17}$ De acordo com Cançado Trindade (2010, p. 44), o fenômeno da multiplicidade dos tribunais internacionais é próprio dos tempos atuais. Os tribunais internacionais contemporâneos têm contribuído decisivamente para a expansão da jurisdição internacional, assim como para a afirmação e consolidação da personalidade e capacidade jurídicas internacionais do ser humano, como sujeito tanto ativo (ante os tribunais internacionais de direitos humanos) como passivo (ante os tribunais penais internacionais) do Direito Internacional. No entanto, apesar deste fenômeno, há que se apontar que na maior parte dos tribunais internacionais o indivíduo não conta com uma participação direta e imediata, necessitando da proteção diplomática do Estado de sua nacionalidade para apresentar suas reclamações perante estes órgãos. Apenas no sistema regional europeu de proteção aos direitos humanos, perante a Corte Europeia de Direitos Humanos, há a previsão, garantia e efetivo funcionamento de mecanismos jurídicos acessíveis diretamente pelos indivíduos, os quais podem apresentar ações, mediante um formulário disponibilizado pela Corte, contra os Estados que ratificaram a Convenção Europeia dos Direitos do Homem, de 1950 (CORTE EUROPEIA DE DIREITOS HUMANOS; CONSELHO DA EUROPA, 2013).

${ }^{18}$ Conforme Clapham (2010, p. 27), o indivíduo pode, hoje, ser responsabilizado criminalmente de forma direta, a partir da decisão do caso Tadic pelo Tribunal Penal Internacional para a Antiga Iuguslávia, bem como pela instituição do Tribunal Penal Internacional, com competência para julgar indivíduos que tenham cometido crimes contra a humanidade, dentre outras situações.

${ }_{19}$ Segundo Dri (2005, p. 9), se a qualificação dos Estados e das organizações internacionais como sujeitos do direito internacional é pacífica doutrinariamente, o mesmo não ocorre com o indivíduo. Embora a personalidade internacional da pessoa humana tenha sido reconhecida por precursores do direito das gentes, como Francisco de Vitória e Hugo Grotius, a doutrina internacionalista inclina-se a não admitir tal característica ou a fazê-lo com severas restrições.
} 
realmente há um espaço concreto para que atuem nas relações internacionais em condições similares ou mesmo igualitárias aos demais sujeitos. Os defensores do reconhecimento do indivíduo como sujeito do direito internacional e das relações internacionais sustentam que há progresso, que há um espaço que vem sendo conquistado, mediante todas as normas e instrumentos de garantia jurídica citados anteriormente, entendendo não ser possível delinear e balizar a atuação do indivíduo na cena internacional pelos mesmos critérios atinentes aos Estados (DRI, 2005, p. 11; CANÇADO TRINDADE, 2002).

Mas, de qualquer forma, no plano concreto, a efetiva participação e garantia de direitos e deveres internacionais aos indivíduos não encontra plenitude, havendo ainda muito a ser construído e revisado na teoria das relações internacionais e no direito internacional para que o indivíduo possa exercer o protagonismo que o as teorias normativas das relações internacionais querem the atribuir. Portanto, para que o exemplo de solidariedade demonstrado no filme "O Porto" possa deixar de ser ficção e de se restringir a atitudes pontuais de poucas pessoas ou comunidades, como as ali retratadas, e ganhe o respaldo oficial dos aparatos institucionais estatais e de organizações internacionais, bem como legitimidade, reconhecimento e apoio de toda a comunidade internacional, há que se repensar os modelos atuais pelos quais as relações internacionais se pautam, parecendo plausível e adequada a retomada e a apropriação, adaptada ao contexto atual, dos preceitos idealistas.

\section{Considerações Finais}

O cenário contemporâneo das relações internacionais apresenta delineamentos diferenciados, que permitem cogitar sobre a inserção de novos atores neste âmbito. Nesse sentido, pertinente é a discussão sobre a possibilidade de reconhecimento do indivíduo como sujeito de direito internacional, influente na formação e execução das relações internacionais.

Em face disso, a fim de compreender a complexidade e abrangência desta questão, a utilização da linguagem cinematográfica para ilustrá-la e sobre ela refletir, parece meio apropriado. Nesse viés, o presente trabalho propôs-se a analisar o filme "O Porto" (Le Havre), que retrata situação envolvendo manifestações de solidariedades entre indivíduos de diferentes nacionalidades em face do contexto da migração ilegal da África para a Europa, para tratar da inserção do indivíduo como ator e sujeito no plano internacional.

Para tanto, escolheu-se abordar o exemplo de solidariedade retratado na referida obra cinematográfica a partir do exame da teoria idealista das relações internacionais, por ter se identificado no enredo do filme situações que ilustrariam alguns de seus principais preceitos, 
questionando se haveria realmente espaço para o indivíduo no cenário internacional atual. Assim, a análise deste filme permitiu pensar sobre a retomada do idealismo nas relações internacionais, como forma de, pela adaptação de alguns de seus conceitos centrais, revisar o modelo pelo qual as relações internacionais hodiernas se pautam, para incrementar o espaço, ainda limitado, em que o indivíduo pode delas participar.

\section{Referências Bibliográficas}

ANGELL, Norman. The Great Illusion. Disponível em: http://www.gutenberg.org/files/38535/38535-h/38535-h.htm>. Acesso em 22 out. 2013.

ASHWORTH, Lucian M. Where are the Idealists in Inter-War International Relations? Limerick Papers in Politics and Public Administration, University of Limerick, Ireland, n. $8,2005$.

Did the Realist-Idealist Great Debate Really Happen? A Revisionist History of International Relations. International Relations, London, vol. 16, n. 1, p.33-51, 2002.

BARNABÉ, G. R. Hugo Grotius e as relações internacionais: entre o direito e a guerra. Cadernos de Ética e Filosofia Política, n. 15, p. 27-47, fev./2009.

BEDIN, Gilmar Antonio. A sociedade internacional e o século XXI: em busca da construção de uma ordem mundial justa e solidária. Ijuí: Unijuí, 2001.

BRUNKHORST, H. Solidarität. Von der Bürgerfreundschaft zur Globalen Rechtsgenossenschaft. Frankfurt/Main: Suhrkamp, 2002.

CAIMI, Mario. Acerca de la Interpretación del Tercero Articulo Definitivo del Ensayo de Kant Zum Ewigen Frieden. In: ROHDEN, Valério (Ed.). Kant e a instituição da paz. Porto Alegre: Editora UFRGS; Goethe-Institut; ICBA, 1997, p.191-200.

CANÇADO TRINDADE, Antônio Augusto. Tratado de Direito Internacional dos Direitos Humanos - Volume II. Porto Alegre: Sergio Fabris Editor,1999.

Os Tribunais Internacionais Contemporâneos e a Busca da Realização do Ideal da Justiça Internacional. Revista da Faculdade de Direito da UFMG, Belo Horizonte, n. 57, p. 37-68, jul./dez. 2010.

A Personalidade e Capacidade Jurídicas do Indivíduo como Sujeito do Direito Internacional. Revista do Instituto Brasileiro de Direitos Humanos, ano 3, vol. 3, n. 3, p. 21 $51,2002$.

CARR, Edward. H. Vinte anos de crise: 1919-1939. Brasília: UNB, 1981.

CLAPHAM, Andrew. The Role of the Individual in International Law. European Journal of International Law, vol. 21, n. 1, p. 25-30, 2010. 
CORTE EUROPEIA DE DIREITOS HUMANOS; CONSELHO DA EUROPA. The ECHR in 50 questions Disponível em: <http://www.echr.coe.int/Documents/50questions_ENG.pdf>. Acesso em 22 out. 2013.

DIAS, Reinaldo. Relações Internacionais: introdução ao estudo da sociedade internacional global. São Paulo: Atlas, 2010.

DRI, Clarissa Franzoi. Do Estado ao Indivíduo: repensando os sujeitos do direito internacional público. Revista da Faculdade de Direito da Universidade Federal do Paraná, v. 43, p. 13-18, 2005.

FILICIANO, Cristiano. Crítica: O Porto. Publicada em 09 mar. 2012. Disponível em: $<$ http://setimacena.com/criticas/critica-o-porto/>. Acesso em 12 out. 2013.

FIPRESCI. Prêmios mais recentes. Disponível em: <http://www.fipresci.org/awards/awards_ndx.htm>. Acesso em 12 out. 2013.

GRIFFITHS, Martin. 50 grandes estrategistas das relações internacionais. São Paulo: Contexto, 2004.

GROTIUS, Hugo. De iure belli ac pacis. Disponível em: <https://ia700408.us.archive.org/6/items/hugonisgrottiide010grotuoft/hugonisgrottiide010grot uoft.pdf $>$. Acesso em 22 out. 2013.

HERRERA, Carlos Miguel. El concepto de solidaridad y sus problemas políticoconstitucionales. Una perspectiva iusfilosófica. Revista de Estudios Sociales, Bogotá, n. 46, p. 63-73, mai./ago. 2013.

KANT, Immanuel. À paz perpétua: um projecto filosófico. 1795. Disponível em: <http://www.lusosofia.net/textos/kant_immanuel_paz_perpetua.pdf>. Acesso em: 22 out. 2013.

LIMA, Francisco Jozivan Guedes. A fundamentação moral das relações internacionais préjurídicas a partir de Kant. Contexto Internacional, Rio de Janeiro, vol. 34, no 2,p. 471-499, jul./dez. 2012.

LITTLE BOB. La Biographie. Disponível em: <http://www.littlebob.fr/littlebob_pagesHTML/littlebob_biographie.htm>. Acesso em 22 out. 2013.

MAGALHÃES, Diego T. D. Conflitos de Teorias das Relações Internacionais sobre a Paz. Implicações Normativas. Relações Internacionais, n. 36, p. 119-136, dez. 2012.

MANGUEL, Alberto. À mesa com o chapeleiro maluco: ensaios sobre corvos e escrivaninhas. São Paulo: Cia das Letras, 2009.

MIALHE, Jorge Luís. Relações internacionais e Direito internacional numa sociedade globalizada: breves anotações. Verba Juris, ano 7, n. 7, p. 205-240, jan./dez. 2008 
MIYAMOTO, Shiguenoli. O ideário da paz em um mundo conflituoso. In: BEDIN, Gilmar Antonio; et. al. (Orgs.). Paradigmas das Relações Internacionais: realismo-idealismodependência-interdependência. 2 ed. Ijuí: Unijuí, 2004.

MORGENTHAU, Hans. Política entre las naciones. La lucha por el poder y por la paz. Buenos Aires: Grupo Editor Latinoamericano, 1985.

MORUS, Thomas. Utopia. Disponível em: <http://www.dominiopublico.gov.br/download/texto/cv000070.pdf>. Acesso em 22 out. 2013.

NOUR, Soraya. À paz perpétua de Kant: filosofia do direito internacional e das relações internacionais. São Paulo: Martins Fontes, 2004.

. Os Cosmopolitas. Kant e os "Temas Kantianos" em Relações Internacionais. Contexto Internacional, vol. 25, n. 1, p. 7-46, jan./jun. 2003.

NUNES, João. Para que serve a teoria das relações internacionais? Relações Internacionais, n. 36, p.11-22, dez. 2012.

O PORTO. Direção de Aki Kaurismäki. Fotografia de Timo Salminen. [S.1.]: Imovision, 2011. 1 DVD (93 min), NTSC, color. Título original: Le Havre.

PÁDUA, Marsílio de. Defensor Pacis. Disponível em: $<$ https://ia700301.us.archive.org/5/items/defensorpacisofm08emer/defensorpacisofm08emer.p df $>$. Acesso em 22 out. 2013.

SAINT-PIERRE, Abbé de. Projeto para Tornar Perpétua a Paz na Europa. Brasília: Editora Universidade de Brasília, IPRI, 2005.

SEITENFUS, Ricardo; VENTURA, Deisy. Introdução ao Direito Internacional Público. 3. ed. Porto Alegre: Livraria do Advogado, 2003.

TERRA, Ricardo Ribeiro. Juízo político e prudência em À paz perpétua. In: ROHDEN, Valério (Ed.). Kant e a instituição da paz. Porto Alegre: Editora UFRGS; Goethe-Institut; ICBA, 1997, p. 222-232.

TRAGL, T. Solidarität und Sozialstaat. Theoretische Grundlagen, Probleme und Perspektiven des Modernen Sozialpolitischen Solidaritätskonzeptes. München; Mering:Hampp, 2000.

TRINDADE, Luciano José. À paz perpétua de Kant e a sociedade internacional contemporânea. Ijuí: Unijuí, 2010.

WALTZ, Kenneth. Teoria das Relações Internacionais. Lisboa: Gradiva, 2002.

WESTPHAL, Vera Herweg. Diferentes matizes da ideia de solidariedade. Revista Katálysis, Florianópolis, vol. 11, n. 1, p. 43-52, jan./jun. 2008. 
ZIMMERN, Alfred. The League of Nations and the Rule of Law. Disponível em: <https://ia700301.us.archive.org/21/items/leagueofnationsa009378mbp/leagueofnationsa0093 78mbp.pdf. > Acesso em 22 out. 2013.

ZOLL, R. Was Ist Solidarität Heute? Frankfurt/Main:Suhrkamp, 2000. 